Original Article

\title{
VALIDATION OF ACCUMULATION OF CAMPTOTHECIN CONTENT, AN ANTI-CANCER ALKALOID IN NOTHAPODYTES NIMMONIANA GRAHAM. IN PHENOTYPIC VARIANTS: METHOD FOR IDENTIFYING HIGH-YIELDING SOURCES OF ALKALOID
}

\author{
ANITA SURENDRA PATIL ${ }^{* 1}$, ANKIT SUBHASH KALE1, SURENDRA RAJARAM PATIL ${ }^{2}$, \\ HARIPRASAD MADHUKARRAO PAIKRAO ${ }^{3}$
}

${ }^{1}$ Lab no 106, Plant Secondary Metabolite Lab, Department of Biotechnology, Sant Gadge Baba Amravati University, Amravati 444602 (M. S.) India, ${ }^{2}$ Dr Panjabrao Deshmukh Krushi Vidhyapeeth Akola (M. S) 444104, ${ }^{3}$ Government Institute of Forensic Science, Aurangabad

(M. S.) India 431004

Email: anitapatil@sgbau.ac.in

Received: 16 Jan 2016 Revised and Accepted: 22 Jul 2016

ABSTRACT

Objective: The study was aimed to find the CPT accumulation, in particular organ, via variable extraction method and in vitro propagation method both qualitatively and quantitatively.

Methods: In the present study, the seven phenotypic variants of $N$. nimmoniana such as dry leaf, fresh barks of plant, induced callus, somatic embryo and suspension culture (In exogenous medium and in pallet) in $100 \mathrm{mg} / \mathrm{ml}$ were analyzed for CPT content by TLC (Thin layer chromatography) and HPLC (High performance liquid chromatography).

Results: TLC and HPLC analysis confirm the presence of CPT in dry leaf, fresh barks of the plant, induced callus and somatic embryo. Out of which bark extracts possessed a maximum amount of CPT, i.e. $377.77 \mu \mathrm{g} / \mathrm{g}$, which supposed to be the first choice of CPT source.

Conclusion: Results conclude that the CPT is present in all samples used except exogenous suspension culture, out of which soxhlet bark extract possesses the maximum amount of CPT.

Keywords: Camptothecin (CPT), Anti-cancer, High-performance liquid chromatography.

(C) 2016 The Authors. Published by Innovare Academic Sciences Pvt Ltd. This is an open access article under the CC BY license (http://creativecommons. org/licenses/by/4. 0/) DOI: http://dx.doi.org/10.22159/ijpps.2016.v8i9.10751

\section{INTRODUCTION}

Nothapodytes nimmoniana (Grah.) Mabb. is a tree of up to 3-8 $\mathrm{m}$ tall from the family Icacinacae. It is an endangered medicinal tree from Western Ghats of India, specially to central and south Maharashtra Sahyadris, some parts of Assam, the Himalayan foot hills, Ceylon, Burma and Thailand. Some vernacular names of Nothapodytes nimmoniana are Ghanera, Durvasane mara, Kalgur, Kalagaura that has been used in various parts according to the local folklore knowledge. Due to excessive harvesting without any concern on habitat loss, the population of this species has been declined by 50 $80 \%$, resulting in its vulnerable status [1].

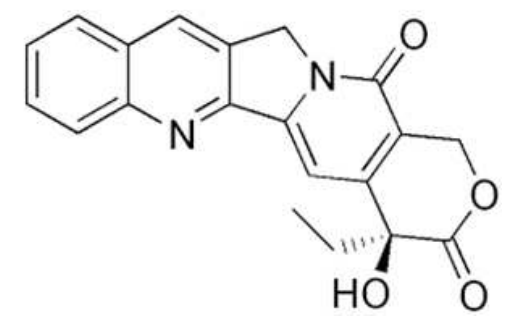

Fig. 1: Structure of camptothecin

Camptothecin (CPT) was first reported in the Chinese tree Camptotheca acuminata [2] and later discovered in N. nimmoniana. The potential of CPT in the treatment of cancer and various diseases has brought interest in the extraction of bioactive compounds and its process optimization from N. nimmoniana. This plant is a rich source of camptothecin-a monoterpene indole alkaloid (Fig. 1), supposed to be most promising anticancer drug [3]. CPT and their derivative are useful as anti-cancer agents in the treatment of tumors [4].
The well-known target of camptothecin is the enzyme, DNA topoisomerase-I. Many analogues of CPT, which possesses potential against various diseases have been synthesized [5]. CPT shows inhibitory prospective against HIV. Furthermore, it is also effective at lung, breast, uterine and cervical cancers [6-8]. Some derivatives of Camptothecin, including topoisan and irinotecan, is in routine practice for the treatment of colorectal and ovarian cancers. CPT reported to shows the cytotoxic effect against Plasmodium falciparum, and thus it can be an interesting molecule for new antimalarial drug discovery [12].

In the present study, we have extracted the CPT from seven phenotypic variants of $N$. nimmoniana in $100 \mathrm{mg} / \mathrm{ml}$ such as dry leaf, fresh leaf, the bark of the plant, induced callus, somatic embryo and suspension culture (in exogenous medium and in a pallet). The characterization, production and quantification of CPT have been validated by TLC analysis and quantification by HPLC.

\section{MATERIALS AND METHODS}

Collection of plant material and identification

The seeds of $N$. nimmoniana were collected from Chiplun part of Western Ghats, Maharashtra. As a part of our research, the plants were germinated and established in our departmental nursery [13]. The plant was authenticated using standard flora and cross-checked and further stored in the herbarium records at Department of Biotechnology, Sant Gadge Baba Amravati University, Amravati, India as N. nimmoniana (J. Graham) with an accession numberBT/SGBAU-07.

\section{Standard CPT sample}

The standard CPT was purchased from Sigma Aldrich Inc, USA, minimum 95\% HPLC grade powder. A stock solution of CPT was prepared by dissolving $100 \mathrm{mg}$ in chloroform: methanol mixture (3:1) [14] and making up the volume to $1 \mathrm{ml}$ with methanol. From 
this stock solution, standard solutions of $20 \mu \mathrm{g} / \mathrm{ml}$ to $100 \mu \mathrm{g} / \mathrm{ml}$ were prepared by transferring aliquots $(0.2$ to $1.0 \mathrm{ml})$ of stock solution to 2 $\mathrm{ml}$ centrifuge tube and adjusting the volume with methanol up to $1 \mathrm{ml}$.

\section{Preparation of experimental samples}

$500 \mathrm{mg}$ each of fresh and dry leaves of $N$. nimmoniana was weighed and crushed in a mortal and pestle with HPLC grade methanol (5 $\mathrm{ml}$ ). The plant bark was sun-dried and crushed to a mesh size of 0.1 to $0.5 \mathrm{~mm}$. About $10 \mathrm{~g}$ of powdered material was kept in a thimble into the solvent extractor and extracted it with $95 \%$ methanol for 9 h. Further, $200 \mathrm{ml}$ of extract was allowed to evaporate at room temperature; it takes approximately 7-8 $\mathrm{d}$ to get the brown gummy solid material measuring about $0.76 \mathrm{gm}$.

Young callus induced by inoculating fresh leaf of $N$. nimmoniana on MS basal medium with 2,4-D (2, 4-Dichlorophenoxyacetic acid) 0.5 $\mathrm{mg} / \mathrm{l}$ and BAP (6-Benzylaminopurine) $3.0 \mathrm{mg} / \mathrm{l}$. Callus induction were observed after 35-40 d of incubation. Further subculturing of callus on similar fresh medium resulted in fragile white callus. Direct somatic embryos were observed from the leaf explants of $N$. nimmoniana cultured on the MS basal medium containing various combinations of TDZ ranging from 0.5 to $3.0 \mathrm{mg} / \mathrm{l}$. After $25 \mathrm{~d}$ of incubation, induction was observed and at $60 \mathrm{~d}$, well-matured embryos were seen on four different concentrations, including 0.5 , $1.5,2.0$ to $3.0 \mathrm{mg} / \mathrm{l}$.

Similarly, fresh fragile callus (approx $4 \mathrm{~g}$ ) of N. nimmoniana was used to establish the suspension culture. The callus was kept in the MS basal salt medium $(400 \mathrm{ml})$ with the sterile $1 \mathrm{mg} / \mathrm{l}$ pectinase enzyme for the separation of cells for 10-15 $\mathrm{d}$. The suspension was subcultured by adding separated cell form above system and kept again for $30 \mathrm{~d}$ for growth of cells $\left(2 \times 10^{4}\right.$ approximately). About $50 \mathrm{ml}$ of suspension was taken into $50 \mathrm{ml}$ centrifuge tube and centrifuged at $2000 \mathrm{rpm}$ for $5 \mathrm{~min}$ at room temperature. The quantity of CPT in filtered supernatant (in exogenous medium) and in the pellet (100 mg of total cells) were determined using HPLC (13).

Experimental sample stock extract $(100 \mathrm{mg} / \mathrm{ml})$ was dissolved in HPLC grade $1 \mathrm{ml}$ methanol and sonicated for about $10 \mathrm{~min}$. It was further centrifuged at $4000 \mathrm{rpm}$ for $10 \mathrm{~min}$ at room temperature. The supernatant was collected in a fresh tube and transferred to HPLC vial by using $0.25 \mu \mathrm{m}$ syringe filter.

\section{Qualitative estimation by TLC}

The confirmation of CPT in experimental extracts was done by TLC. The TLC plate was prepared on $15 \times 10 \mathrm{~cm}$ glass plates coated with silica gel slurry, dried in room temperature and kept in the oven for activation at $110^{\circ} \mathrm{C}$ for 1 hour. About $20 \mu$ l of extract was spotted onto the silica plate in line spotting. The experimental plates were developed in a chromatographic chamber, saturated by solvent system $(100 \mathrm{ml})$ Ethyl acetate: Methanol $(3: 1)[13,15]$. The plate was allowed to develop for 10-15 min, air dried and observed under UV transilluminator (Cleaver) at $365 \mathrm{~nm}$. The $\mathrm{R}_{\mathrm{f}}$ values of the CPT were calculated by the given formula and compared with standard CPT.

$$
\mathrm{R}_{\mathrm{f}}=\frac{\text { Distance traveled by sample }}{\text { Distance traveled by Solvent }}
$$

\section{Quantification by HPLC}

\section{Preparation of the calibration curve for camptothecin}

Standard solutions of CPT in 20,40,60, 80 and $100 \mu \mathrm{g} / \mathrm{ml}$ was injected in HPLC column. The peaks were detected at $365 \mathrm{~nm}$. Calibration curves of CPT were prepared by plotting peak area vs. concentration. The CPT concentration in various samples was obtained by plotting the values in the standard graph.

\section{HPLC analysis}

The experimental sample solutions for HPLC were filtered using 0.2 $\mu \mathrm{m}$ syringe filter before injection. The instrument was purchased from Agilent Technologies (Model-1260 Infinity) and column used was ZORBAX Eclipse plus C18 $(4.6 \times 100 \mathrm{~mm}, 3.5)$. Acetonitrile: Water (25:75) solvent system with flow rates $1 \mathrm{ml} / \mathrm{min}$ was selected [13]. Detection of CPT was done at $365 \mathrm{~nm}$; isocratic gradient elution was followed for a sample volume of $10 \mu$. The flow rate was kept at $1 \mathrm{ml} / \mathrm{min}$. Standard CPT from Sigma-Aldrich $(1 \mathrm{mg} / \mathrm{ml})$ was used as the reference compound.

\section{Statistical analysis}

All data were subjected to statistical analysis following Completely Randomized Design. The means were subjected to \pm SEM.

\section{RESULTS}

\section{TLC analysis}

TLC plate developed at $365 \mathrm{~nm}$ was analyzed under UV transilluminator. A total of seven samples along with standard CPT (20 $\mu$ ) were loaded on TLC plate as line spots from Lane 1-8 (Shown in fig. 3). Lane 1 shows standard CPT band at $R_{f} 0.83$, which is common in all test sample bands from Lane 2-6. The results confirm the presence of CPT in all test samples (fresh leaf, dry leaf bark, callus, somatic embryo and suspension culture with cells) except seventh sample of suspension culture (exogenous type) without cells. Fig. 3 also revealed that CPT concentration was highest in methanolic bark extract, extracted in soxhlet apparatus, followed by dry leaf, fresh leaf, callus, somatic embryo and least in suspension culture.

\section{HPLC analysis}

The actual amount of CPT present in the samples was confirmed by HPLC using the standard CPT graph (fig. 5). The CPT content in the 100 $\mathrm{mg} / \mathrm{ml}$ methanolic extracts of fresh leaf, dry leaf, bark, fresh callus, somatic embryo and suspension culture of $N$. nimmoniana were analyzed and quantified by HPLC method. The chromatogram obtained shows homogenous peaks of CPT in all samples except exogenous suspension culture with baseline separation at similar retention time $7.05 \mathrm{~min}$, same as that of standard CPT. The exact retention time of test samples and standard CPT along with overlapping peaks confirms the presence of CPT in all samples. Although the variation in peak size related with types of explants used for experimentation and extraction method. The chromatogram confirms that the CPT is absent in Exogenous Suspension Culture (fig. 4).

The estimations of CPT present in samples were performed on HPLC by preparing a calibration graph (fig. 5: Area v/s CPT amount in $\mu \mathrm{g} / \mathrm{ml}$ ) with Y-equation $=1.33513 \mathrm{x}+1.97716$ (error 0.00005). The CPT peaks of all samples including standard CPT were noted down as per fig. 5 .

The amount of CPT present in test samples was calculated by putting the peak area value in automated generated calculator in the instrument. The results confirm that CPT content is maximum in Bark soxhlet extract i.e. $377.77715 \pm 2.52307 \mu \mathrm{g} / \mathrm{g}$ with the largest peak area of 3307929 on the chromatogram, (generated by AgilentEZ Chrom Elite HPLC-based software) which was followed by dry leaf, fresh leaf, callus, somatic embryo and suspension culture as shown in table 1 . During the analysis, one of the derivatives of CPT, 9-methoxy CPT was visible in chromatogram at a retention time of 13.25 min. The fig. 4 confirms that 9-methoxy CPT was present in fresh leaf, dry leaf and soxhlet extract, were as in another experimental sample it was missing.
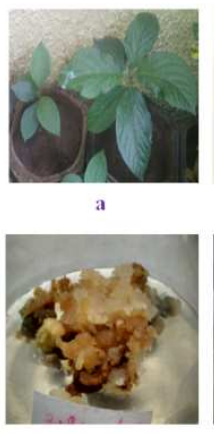

d
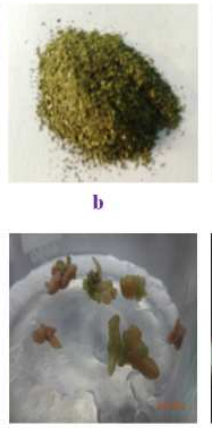

e
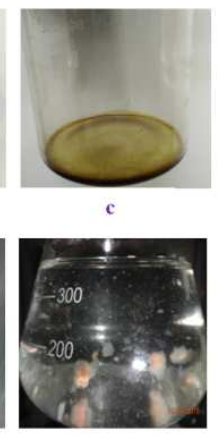

$\mathrm{f}$

Fig. 2: Various phenotypic explants used for comparative CPT extraction and quantification, a. Fresh leafs; $b$. Dried leaf powder; c. Methanolic extract of bark; d. Young callus; e. Somatic embryos and f. Suspension culture 


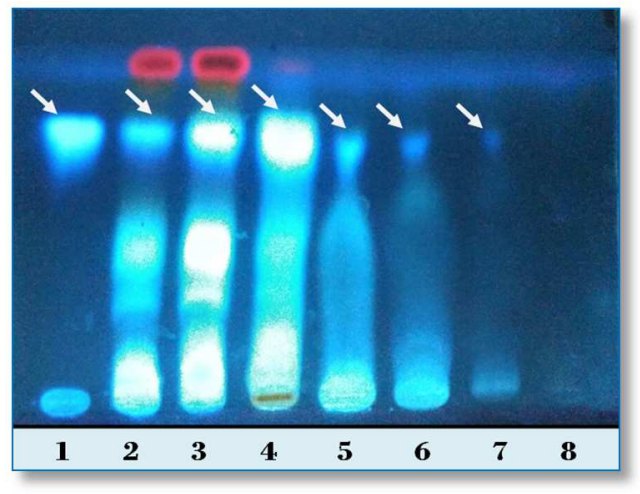

Fig. 3: TLC analysis of camptothecin isolated from fresh leaf, dry leaf bark, callus, somatic embryo and suspension culture of $N$. nimmoniana along with standard Camptothecin (Lane 1:

Standard CPT, Lane 2: Fresh Leaf, Lane 3: Dry Leaf, Lane 4: Bark, Lane 5: Fresh Callus, Lane 6: Somatic Embryo, Lane 7: Cells of Suspension Culture, Lane 8: Exogenous Suspension Culture).

\section{DISCUSSION}

Nowadays, Camptothecin and their derivatives are important anticancer plant drugs $[16,17]$. The plants reported producing CPT include Camptotheca acuminata, N. nimmoniana, Tabernaemontana heyneana and Ophiorrhiza rugosa $[1,16-21]$. Many researchers have taken initiative for the extraction, purification and characterization of Camptothecin from various parts of N. nimmoniana [22]. In the light of above the research, our study deals with TLC confirmation and HPLC quantitative analysis of CPT isolated from seven different phenotypic variants of $N$. nimmoniana collected from Western Ghats of Maharashtra.

As TLC is used for identification and confirmation of herbal drugs, it shows a complete fingerprint of the compounds presents in the mixture. The TLC separation of CPT in N. nimmoniana has been discussed by many workers $[15,23,24]$. The CPT isolated from phenotypic variants of $N$. nimmoniana confirms the band to significant $\mathrm{R}_{\mathrm{f}} 0.83$ as earliest reports $[13,15]$. Confirmation and quantification of CPT from the high-yielding variants of $N$. nimmoniana were done by HPLC analysis. In earlier reports, the CPT was estimated to be $0.4-0.5 \%$ in C. acuminata[18], $0.23 \%-0.33 \%$ in N. nimmoniana [1] and $0.00013 \%$ in T. heyneana stem bark [20]. Similarly about $0.075 \%$ CPT in shoots of mature trees of $N$. nimmoniana [24]. Initially $0.081 \%$ camptothecin content from leaf samples with retention time $3.5 \mathrm{~min}$ at a flow rate of $1.6 \mathrm{ml} / \mathrm{min}$ reported [1], which was modified in earlier studies [13], with 7.05 min retention time (flow rate- $1 \mathrm{ml} / \mathrm{min}$ ) used in the present study. This change in retention time could be due to change in solvent system and flow rate.

In in vivo study, the presence of CPT and 9-Methoxy CPT in $N$. nimmoniana was confirmed [4]. The 9-Methoxy camptothecin is one of the important antitumor compounds in Nothapodytes foetida [25] reported to inhibited Topoisomerase-I [26]. In the comparative antitumor activity of CPT and 9-Methoxy CPT against murine sarcoma S180 tumour cells, 9-Methoxy CPT shows lower $\mathrm{IC}_{50}$ as compared to CPT [27]. The low yield of 9-Methoxy CPT has been reported in $N$. foetida and $C$. acuminata $[28,29]$. Furthermore, low 9MCPT content as compared to CPT isolated from distinctive plant parts of $N$. nimmoniana collected from different geographical regions of Western Ghats of India [30]. Our study further confirmed the presence of CPT in various phenotypic variants along with its presence in different plant parts, as is visible in HPLC chromatogram (fig. 4).

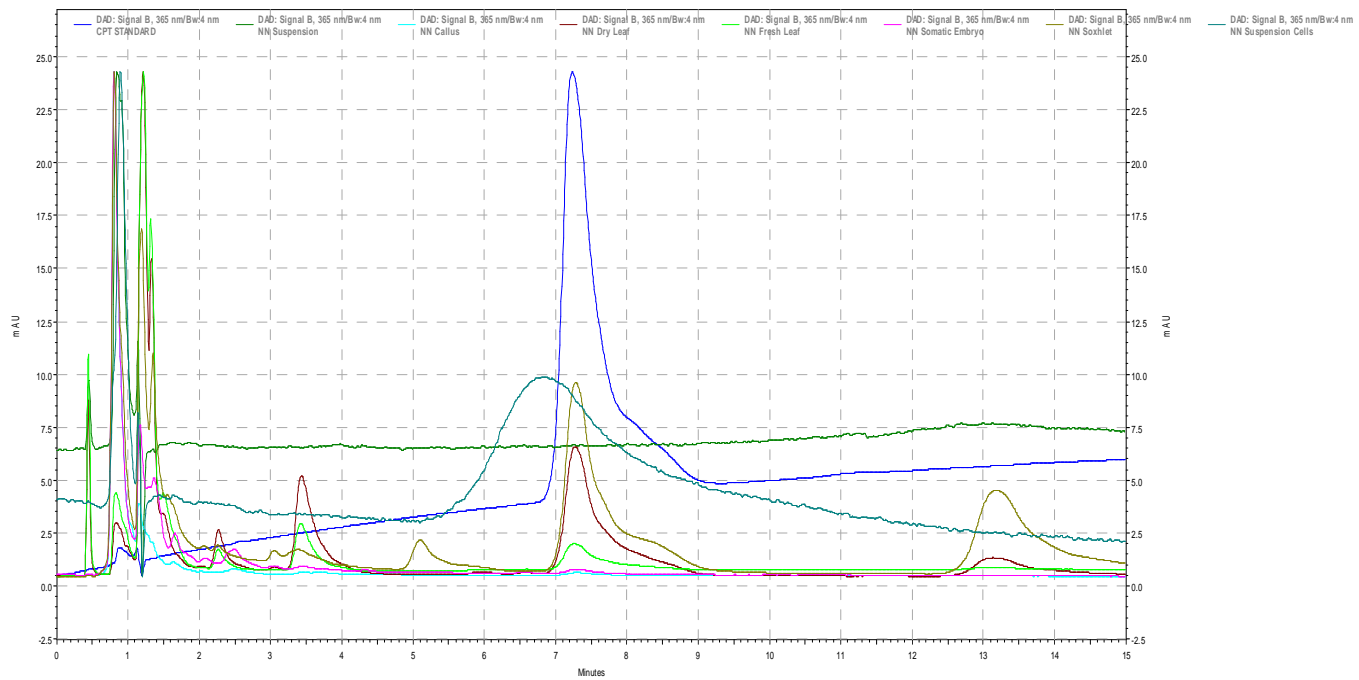

Fig. 4: HPLC determination of Camptothecin isolated from fresh leaf, dry leaf, bark, callus, somatic embryo and suspension culture of $N$. nimmoniana along with standard (CPT Retention time $=7.05 \mathrm{~min}$ )

Table 1: Quantitative estimation of CPT by HPLC, isolated from fresh leaf, dry leaf bark, callus, somatic embryo and suspension culture of N. nimmoniana along with standard camptothecin

\begin{tabular}{llll}
\hline S. No. & Name of the sample & Peak area & Crude extract $(\boldsymbol{\mu g} / \mathbf{g}) \pm$ SEM \\
\hline 1 & Fresh Leaf & 234082 & $26.54505 \pm 0.11224$ \\
2 & Dry Leaf & 1770418 & $202.4064 \pm 1.01784$ \\
3 & Soxhlet Bark extract & 3307929 & $377.7715 \pm 2.52307$ \\
4 & Fresh Callus & 51941 & $5.89014 \pm 0.17066$ \\
5 & Fresh Somatic Embryo & 15349 & $1.74058 \pm 0.08064$ \\
6 & Suspension Cell Culture & 16504 & $1.87159 \pm 0.24507$ \\
7 & Exogenous Suspension culture & - & - \\
\hline
\end{tabular}

Note: Standard stock $100 \mathrm{mg} / \mathrm{ml}$ for test samples solutions. All the data was statistically analyzed \pm SEM represent standard error of mean and $\mathrm{n}=3$. 


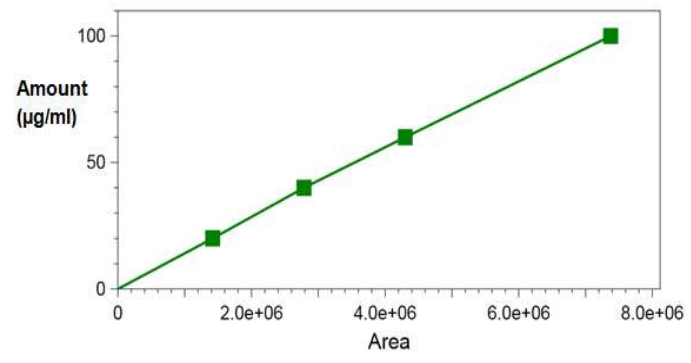

Fig. 5: Calibration graph of CPT standard $(20 \mu \mathrm{g} / \mathrm{ml}$ to 100 $\mu \mathrm{g} / \mathrm{ml}$ ) with Y-equation $=1.33513 \mathrm{x}+1.97716$ (error 0.00005$)$

In tissue culture efforts for CPT accumulation in callus culture, showed the traces of both CPT and 9-methoxy CPT [24, 31], as we have demonstrated and confirmed CPT was present in the small amount in callus culture, somatic embryo and suspension culture in this paper, but 9-MCPT was absent. This may be due to different hormones used in tissue culture. Initially, production of CPT by callus culture and suspension culture from N. nimmoniana has been established [32], which suggest the lower yield of CPT in $N$. nimmoniana in vitro $(0.0003 \%-0.01 \%)[24,33]$.

\section{CONCLUSION}

In the present study, camptothecin was detected at a flow rate of 1.0 $\mathrm{ml} \mathrm{min}-1$ and by using the mobile phase in an isocratic mode, without altering the solvent pumping throughout the course of HPLC run.

In the present study, the content of CPT in bark extract was found to be highest $(377.7715 \pm 2.52307 \mu \mathrm{g} / \mathrm{g})$ as compared to other experimental samples. This variation may be due to physiological variation from different culture environment viz. plant growth regulator or temperature or stress.

The callus and somatic embryo cultures did not produce the appreciable amount of secondary metabolites comparable to that of intact plants. This might be because secondary metabolite production is lesser in cultures due to the lesser organization. Secondary metabolites accumulate less in undifferentiated tissues than in differentiated tissues. The production of secondary metabolites in in-vitro cultures may be enhanced by using some specialized techniques like hairy root cultures, precursor feeding or use of mutational techniques for appreciable results.

\section{ACKNOWLEDGEMENT}

The authors are thankful for the support provided by the UGC, New Delhi (F. No 42-212/2013 (SR)) in carrying out the present research work. We are also thankful to Department of Biotechnology, SGBAU, Amravati (M. S) for providing the research facilities.

\section{ABBREVIATION}

mg-milligram, CPT-Camptothecin, 9-MCPT-9-methoxy Camptothecin, TLC-Thin Layer Chromatography, HPLC-High Performance Liquid Chromatography, Min-Min, $\mu \mathrm{g}$-microgram, $\mu \mathrm{l}$-microliter, ml-milliliter, $\mathrm{cm}$-centimeter, rpm-round per min, $\mu \mathrm{m}$-micrometer, \%-Percentage, $\mathrm{mg} / \mathrm{l}$-milligram/liter, mm-millimeter, Rf-Retardation factor, TDZThidiazuron, MS = Murashige and Skoog

\section{CONFLICT OF INTERESTS}

Authors have no conflict of interest.

\section{REFERENCES}

1. Padmanabh BV, Chandrashekhar M, Ramesh BT, Hombegowda HC, Gunaga RP, Suhas S, et al. Pattern of accumulation of camptothecin anticancer alkaloids in Nothapodytes nimmoniana, Graham in Western Ghats, India, implications for high yielding sources of alkaloids. Curr Sci 2006;90:95-100.

2. Wall ME, Wani MC. Plant antitumor agents II: the structure of two new alkaloids from Camptotheca acuminate. J Org Chem 1968;34:1364-7.
3. Nalawade SM, Abhay PS, Lee CY, Kao CL, Tsay HS. Studies on tissue culture of Chinese medicinal plant resources in Taiwan and their sustainable utilization. Bot Bulla Acad Sci 2003;44:79-98.

4. Govindachari TR, Viswanathan N. Alkaloids of Mappia foetida. Phytochem 1972;11:3529-31.

5. Wall ME, Wani MC. CPT and Analogs: From Discovery to Clinic, CRC Press: Boca Raton; 1995. p. 21-41.

6. Priel E, Showalter SD, Blair DG. Inhibition of human immunodeficiency virus (HIV-l) replication in vitro by noncytotoxic doses of CPT, a topoisomerase inhibitor. Aids Res Hum Retroviruses 1991;7:65-72.

7. Takeuchi A, Dohashi K, Fujimoto S, Tanaka K, Suzuki M. A late phase II study of CPT-II in uterine, cervical cancer and ovarian cancer. Jpn J Cancer Chemother 1991;18:1661.

8. Potmesil M. CPT from bench research to hospital. Cancer Res 1994;54:1431-9.

9. Lilenbaum RC, Ratain MJ, Miller AA, Hargis JB, Hollis DR, Rosner GL, et al. Phase I study of paclitaxel and topotecan in patients with advanced tumors: a cancer and leukemia group B study. J Clin Oncol 1995;13:2230-7.

10. Romanelli SP, Perego G, Pratesi N, Carenini M, Zunino TF. In vitro and in vivo interaction between cisplatin and topotecan in ovarian carcinoma systems. Cancer Chemother Pharmacol 1998;41:385-90.

11. Vladu B, Jan W, Manikumar MG, Mansukhlal C, Wani ME, Wall ME, et al. 7-and 10-Substituted camptothecin: dependence of topoisomerase I-DNA cleavable complex formation and stability on the 7 and 10-substituents. Mol Pharmacol 2000;57:243-51.

12. Bdley AF, Cumming JN, Shapiro TA. Effect of CPT, a topoisomerase I inhibitor, on Plasmodium falciparum. Biochem Pharmacol 1998;55:709-11.

13. Patil A, Patil S, Mahure S, Kale A. UV, FTIR, HPLC confirmation of camptothecin an anticancer metabolite from bark extract of Nothapodytes nimmoniana (J. Graham). A J Ethnol 2014; 1:174-85.

14. Sharma S, Kumar A, Namdeo AG. Pharmacognostical and phytochemical analysis of Nothapodytes nimmoniana stem. Int J Pharm Pharm Sci 2012;4:455-9.

15. Lokesh P, Balasubramanya S, Anuradha M. Cost effective quantification of camptothecin and a comparative study of its content in Nothapodytes foetida and Ophiorrhiza mungos sourced from selected geographical locations. Oriental Pharm Exp Med 2014;14:87-92.

16. Takeuchi A, Dohashi K, Fujimoto S, Tanaka K, Suzuki M, Terashima Y, et al. A late phase II study of CPT-II in uterine, cervical cancer and ovarian cancer. Jpn J Cancer Chemother 1991;8:1661-89.

17. Potmesil M. Camptothecins: from bench research to hospital wards. Cancer Res 1994;54:1431-9.

18. Van-Hengel AJ, Harkes MP, Wichers HJ, Hesselink PGM, Buitelaar RM. Characterization of callus formation and camptothecin production by cell lines of Camtotheca acuminata. Plant Cell Tissue Organ Cult 1992;28:11-8.

19. Aiyama R, Hisako N, Nokata K, Shinohara C, Sawada SA. A Camptothecin derivative from Nothapodytes nimmoniana. Phytochemistry 1988;27:3663-4.

20. Gunasekera SP, Badawi MM, Cordell GA, Farnsworth NR, Chitnis M. Plant anticancer agents and isolation of camptothecin and 9-methoxy camptothecin from Ervatamia heyneana. J Nat Prod 1979;42:475-7.

21. Gharpure G, Chavan B, Lele U, Hastak A, Bhave, Malpure N, et al. Camptothecin accumulation in Ophiorrhiza rugosa var. prostrata from Northern Western Ghats. Curr Sci 2010;302-4.

22. Namdeo AG, Sharma A. HPLC analysis of camptothecin content in various parts of Nothapodytes foetida collected on different periods. Asian Pac J Trop Biomed 2012;2:389-93.

23. Fulzele D, Satdive RK. Comparison of techniques for the extraction of the anti-cancer drug camptothecin from Nothapodytes foetida. J Chromatogr A 2005;1063:9-13.

24. Roja G, Heble MR. The quinoline alkaloids camptothecin and 9methoxycamptothecin from tissue cultures and mature trees of Nothapodytes nimmoniana. Phytochemistry 1994;36:65-6. 
25. Hsiao HY, Cheng TJ, Yang GM, Huang IJ, Chen RLC. Determination of camptothecins in DMSO extracts of Nothapodytes foetida by direct injection capillary electrophoresis. Phytochem Anal 2008;19:136-40.

26. Wu TS, Leu YL, Hsu HC, Ou FF, Chen CC, Chen CF, et al. Constituents and cytotoxic principles of Nothapodytes foetida. Phytochemistry 1995;39:383-5.

27. Liaoa N, Zhang $\mathrm{P}$, Ao $\mathrm{M}$, Wang J, Shi $\mathrm{Y}$, Yu L. 9methoxycamptothecin from Nothapodytes foetida induces apoptosis in Murine sarcoma S180 cells. Z Naturforsch C 2011;66:471-6.

28. Wiedenfeld H, Furmanowa M, Roeder E, Guzeoska J, Gustowski. Camptothecin and 10-hydroxy camptothecin in callus and plantlets of Camptotheca acuminate. Plant Cell Tissue Organ Cult 1997;49:213-8.

29. Pirillo A, Verotta L, Gariboldi P, Torregiani E, Bombardell E. Constituents of Nothapodytes foetida. J Chem Soc Perkin Trans 1995; $1: 583$

30. Kavitha P, Vasantha Kumar T, Rajasekharan PE, Abdul Kareem VK, Rao VK. Camptothecin and 9-methoxy camptothecin, anti- cancer alkaloids in Nothapodytes nimmoniana from Western Ghats, India. J Med Aromat Plant Sci 2010;32:129.

31. Thengane SR, Kulkarni DK, Shrikhande VA, Joshi SP, Sonawane $\mathrm{KB}$, Krishnamurthy KV. Influence of medium composition on callus induction and camptothecin(s) accumulation in Nothapodytes foetida. Plant Cell Tissue Organ Cult 2003; 72:247-51.

32. Fulzele DP, Satdive RK, Pol BB. Growth and production of camptothecin by cell suspension cultures of Nothapodytes foetida. Planta Med 2001;67:150-2.

33. Ciddi V, Shuler ML. Camptothecin from callus cultures of Nothapodytes foetida. Biotechnol Lett 2000;22:129-32.

\section{How to cite this article}

- $\quad$ Anita Surendra Patil, Ankit Subhash Kale, Surendra Rajaram Patil, Hariprasad Madhukarrao Paikrao. Validation of accumulation of camptothecin content, an anti-cancer alkaloid in nothapodytes nimmoniana graham. In phenotypic variants: a method for identifying high-yielding sources of alkaloid. Int J Pharm Pharm Sci 2016;8(9):19-23. 